\title{
Criminologías feministas, investigación y cárceles de mujeres en España
}

\author{
Elisabet Almeda Samaranch \\ Universitat de Barcelona \\ elisabet.almeda@ub.edu
}

Recepción: 08-06-2016

Aceptación: 10-02-2017

\section{Resumen}

El objetivo del artículo es analizar el desarrollo de las investigaciones sobre la ejecución penal femenina en el Estado español a lo largo de los últimos treinta años, en el marco de los principales debates e ideas de las "criminologías feministas anglosajonas». Tratar los hitos clave de estos enfoques feministas, las principales dificultades que ha atravesado, las autoras y los autores más relevantes que han liderado este debate intelectual y académico, las interconexiones entre las investigaciones y la acción de los poderes públicos y, finalmente, las temáticas y los enfoques más significativos que se han ido debatiendo desde una perspectiva crítica y no androcéntrica. El estudio de las cárceles de mujeres y de las mujeres encarceladas ha sido, en España, un tema largamente olvidado por la academia, especialmente por la investigación sociológica, que no le ha prestado la atención que merecía hasta recién entrado el siglo XXI. Desde entonces, imbuidas de las ideas y de las reflexiones de las «criminologías feministas anglosajonas", han ido emergiendo distintas investigaciones que las visibilizan y ponen de relieve la importancia de examinar estas instituciones de reclusión a la luz de las nuevas formas de control punitivo hacia las mujeres.

Palabras clave: criminología; mujeres; cárceles; España; feminismo; investigación

\section{Abstract. Feminist Criminologies, Research and Women's Prisons in Spain}

The aim of this article is analyse the development of Spanish research on female offending and incarceration over the last thirty years in the framework of the main debates and ideas of the English feminist criminologies. From a critical, non-androcentric perspective, this article examines the key milestones of these feminist approaches, the main difficulties they have encountered, the most relevant authors that have led this intellectual and academic debate, the interconnections between research and public policies and, finally, the most significant approaches and topics that have been discussed. The study of women's prisons and women prisoners has been overlooked by academia in Spain, especially in sociological research that paid little attention to the topic until the beginning of the 21 st century. Since then, imbued with the ideas of the English feminist criminologies, investigations have emerged that make them visible and evidence the importance of examining these imprisonment institutions in the light of new forms of punitive control towards women.

Keywords: criminology; women; prisons; Spain; feminism; research 


\section{Sumario}

$\begin{aligned} \text { 1. Introducción } & \text { 4. Investigaciones sobre cárceles } \\ \text { 2. Las influencias de las criminologías } & \text { de mujeres en España } \\ \text { feministas en el estudio de las cárceles } & \text { desde comienzos del siglo xxi } \\ \text { y las mujeres presas en España } & \text { 5. Producciones institucionales en } \\ \text { 3. Cárceles de mujeres en el Estado } & \text { el nuevo contexto político y normativo } \\ \text { español: primeros estudios } & \text { lo penitenciario femenino español } \\ \text { de finales del siglo xx } & \text { 6. Reflexiones finales } \\ & \text { Referencias bibliográficas }\end{aligned}$

\section{Introducción}

En una compilación reciente de los cincuenta principales pensadores sobre criminología desde el siglo XVIII hasta finales del siglo XX (Hayward et al., 2010), se verifica que solo hay ocho mujeres seleccionadas. De los cincuenta, seis han investigado extensamente sobre las mujeres y el sistema de justicia criminal: uno es Lombroso y las cinco restantes son mujeres que han trabajado desde perspectivas críticas y feministas que cuestionan las teorías lombrosianas: Pat Carlen, Frances Heidensohn, Meda Chesney-Lind, Carol Smart y Rosa del Olmo. De estas cinco relevantes académicas, cuatro son anglosajonas y una sola no lo es (Del Olmo, catalana que se exilió y radicó en América Latina).

Las criminologías feministas (liberales, marxistas, radicales, postmodernas, negras o multirraciales, entre otras) crecieron a la par que los movimientos de mujeres de la década de 1970 y como respuesta al dominio masculino en las principales corrientes criminológicas (Renzetti, 2013). Ello no solamente implicaba que las mujeres habían sido excluidas de la investigación criminológica, sino que prácticamente no habían sido ni sujetos de investigación. Las únicas referencias a sus personas por parte de la criminología habían sido las teorías sexistas de los fundadores del positivismo criminológico, Lombroso y Ferrero (1895), y la de sus descendientes académicos, los funcionalistas Pollack (1961) y Thomas (1967), que fueron los únicos que estudiaron a las mujeres "delincuentes» de manera "científica» — con todos sus estereotipos sexistas y sus explicaciones biologicistas y psicologistas-. Los continuadores actuales de esta tradición analítica, si bien no defienden las tesis lombrosianas a capa y espada, tampoco han incorporado perspectivas diferenciales teniendo en cuenta el género ni otras variables que no sean conductuales, antropomórficas o biologicistas (Mednick [1987] o Cowen [1979], entre otros). Por su parte, la criminología crítica y la sociología de la desviación de los años setenta desarrolló un pensamiento crítico a los enfoques lombrosianos generales, pero no hizo lo mismo sobre los que versaban específicamente sobre las mujeres. Así, prestigiosos criminólogos críticos, como David Garland y Löic Wacquant, ofrecen algunas herramientas analíticas útiles para el estudio de las distintas formas de encarcelamiento en las sociedades contemporáneas. Pero, tal como 
acertadamente señala Loraine Gelsthorpe (2010), estos prestan una limitada atención a las contribuciones que ha hecho la criminología feminista. Son las sociólogas y/o las criminólogas feministas las que cuestionan por primera vez esas teorías androcéntricas de la delincuencia femenina. Es gracias a los escritos de dichas sociólogas y criminólogas que toda esa crítica tendrá eco significativo en la criminología imperante, con amplias consecuencias en el desarrollo del pensamiento criminológico contemporáneo.

En ese contexto, el estudio de los sistemas de ejecución penal femenina en España -y, concretamente, de las cárceles de mujeres y las mujeres encarceladas - es un tema largamente olvidado por su academia hasta entrado el siglo Xxi. Desde entonces, imbuidas de las ideas y de las reflexiones de las "criminologías feministas anglosajonas», han ido emergiendo distintas investigaciones que las visibilizan y que ponen de relieve la importancia de examinar dichas instituciones de reclusión, a la luz de las nuevas formas de control punitivo hacia las mujeres.

En el presente artículo, se analiza, en primer lugar, las claves de estos enfoques feministas anglosajones y sus autoras y autores más relevantes que constituyen el marco donde, en segundo lugar, se examina más profusamente la evolución de las investigaciones realizadas en el Estado español a lo largo de los últimos treinta años, especialmente desde comienzos del siglo XXI, cuando han proliferado conformando ya una línea de investigación crítica y feminista sobre la ejecución penal femenina en España. Se presentan las principales autoras, autores e investigaciones que han liderado este debate intelectual y académico, las interconexiones entre las investigaciones y la acción de los poderes públicos, así como, finalmente, las temáticas y los enfoques más significativos que se han ido debatiendo, contrastando empíricamente y conformando desde una perspectiva crítica y no androcéntrica.

\section{Las influencias de las criminologías feministas en el estudio de las cárceles y las mujeres presas en España}

Los análisis críticos de las teorías positivistas del siglo xIX sobre la delincuencia y la ejecución penal femenina empiezan a desarrollarse a mediados de los años sesenta y principios de los años setenta del siglo xx. Es especialmente en los países anglosajones donde irrumpen con gran fuerza los primeros trabajos elaborados por mujeres, sociólogas y/o criminólogas con perspectivas críticas y feministas, sean del Reino Unido (Smith, 1962; Heidensohn, 1968; Gibson, 1976; Crites, 1976; Smart, 1976) o de Estados Unidos de Norteamérica o Canadá (Ward y Kassebaum, 1966; Giallombardo, 1966; Bertrand, 1969; Adler, 1975, entre otras). En pleno auge de los movimientos feministas de liberación de las mujeres, estas autoras empiezan a visibilizar la criminalidad femenina dentro de la literatura criminológica y sociológica, en donde prácticamente no existían referencias al respecto, a excepción de las citadas tesis positivistas de finales del siglo XIX, con explicaciones biologicistas y sexistas de las causas de la delincuencia femenina. Entre otros temas, sus investigaciones se 
inician cuestionando esas tesis, destacando las causas sociales de la delincuencia, las respuestas diferenciales de las mujeres y los hombres al encarcelamiento; criticando el modelo androcéntrico del sistema penal — construido para la criminalidad masculina y su castigo-, así como los enfoques también androcéntricos de la criminología y del derecho que construye «sujetos sexuados» o visibilizando la victimización de las mujeres, en particular, de la violencia física y sexual contra ellas.

A esta primera etapa pionera, le seguirá una segunda mucho más fecunda a partir de los años ochenta y noventa. Se trata de un ámbito científico innovador y dinámico sobre el estudio de las transgresiones femeninas a la ley penal y los castigos correspondientes que se va consolidando, a nivel internacional, marcando nuevas líneas teóricas y desafíos a las ciencias sociales actuales, particularmente a la criminología. Especialmente en los últimos quince años, las bases teóricas de las perspectivas críticas y feministas se han ido ampliando, profundizando y complejizando más, al amparo legal de las Reglas de Bangkok (Organización de las Naciones Unidas, 2011). No obstante, en la fase de neoliberalismo global, ello debe confrontarse con otros nuevos y a menudo ampliados e internacionalizados controles punitivos de sus transgresiones, más sutiles pero muchas veces igual o más misógenos que los tradicionales. Ello es lo que puede observarse en los nuevos enfoques críticos y feministas surgidos a la luz de la realidad de muchos países de América Latina (ver, en el monográfico en el que se incluye este artículo, el trabajo de Almeda y Di Nella), así como de algunos países europeos (como España — que son objeto de un estudio pormenorizado en los apartados posteriores-, Francia e Italia, entre otros).

En efecto, en Francia, los estudios pioneros los realizó el criminólogo y penalista Robert Cario (1989a y 1989b) y, en el caso de Italia, la socióloga Franca Faccioli (1982). Junto a otros colegas, los sociólogos Enzo Campelli y Valeria Giordano, y la filósofa y socióloga jurídica Tamar Pitch —muy reconocida dentro el feminismo italiano- publicaron, años después, una investigación excelente sobre las cárceles de mujeres en ese país (Campelli et al., 1992). Todos estos trabajos reflexionan teóricamente sobre el tema de la delincuencia femenina, aportando también muchos datos sobre las cárceles de mujeres de estos países, sobre las mujeres encarceladas y también distintas voces de presas. Cario, Pitch y sus colegas demuestran, con datos, reflexiones y argumentos, el carácter discriminatorio de las cárceles de mujeres francesas e italianas; la predominancia de los tratamientos penitenciarios diferenciales y estigmatizantes para las presas y los mayores y excesivos controles disciplinarios hacia sus conductas y resistencias a la autoridad. Por último, esas producciones son continuadas hasta la actualidad por diversos trabajos muy interesantes, como los de las italianas Claire Renzetti (2013) sobre las "criminologías feministas» y Thea Giacobee (2014), que corrobora muchas de estas ideas para las cárceles femeninas de la Sicilia actual.

No obstante, en este segundo período, las autoras anglosajonas continúan acaparando la mayor parte de las publicaciones, con lo que ejercen una clara 
influencia que pervive hasta la actualidad ${ }^{1}$. Si bien algunas de estas autoras son las mismas del período precedente porque siguieron trabajando sobre el tema, la producción de estudios e investigaciones sobre la criminalidad femenina y las instituciones de encierro de mujeres se multiplica y se diversifica. Con el Reino Unido como país cuna de estas investigaciones, seguido de los Estados Unidos de América y un poco más lejos de Canadá y Australia, se configura un gran abanico de estudios feministas escritos en inglés que versan sobre las mujeres y el sistema de justicia criminal: Carlen (1983, 1990 y 1998; Carlen et al., 1985, con Worrall, 1987 y 2004), Farrington y Morris (1983), Heidensonh (1985), Dobash et al. (1986), Seear y Player (1986), Genders y Player (1987), Josie O’Dwyer et al. (1987), Naffine (1987), Morris (1987), Daly y Chesney-Lind (1988), Chesney-Lind (1989), Gelsthorpe (2010, con Morris, 1990 y 2002), Worrall (1990) y con Gelsthorpe (2009), Carrington (1993), Hahn y Heidensohn (1995), Davis (1996), Davis y Bhavnani (2000), Bertrand (1994 y 1996), Comack (1999), Bosworth (1999), Bosworth y Carrabine (2001), Hanna-Moffat (2001), Burgess-Proctor (2006), Haney (2010), Bernard (2012), Chesney-Lind y Morash (2013), Renzetti (2013) y Barberet (2014), entre muchas otras.

La mayoría de estas autoras se han de ubicar en el marco de la criminología crítica o en lo que se ha venido denominando, desde las diferentes perspectivas feministas en el seno de la criminología, «criminología crítica feminista» o "criminología del género» (Gelsthorpe y Morris, 1990; Hahn y Heidensohn, 1995). Como señala Chesney-Lind, hay que preguntarse si la macho criminology puede reinventarse o si, más bien, «it can be engendered» como disciplina (Hahn y Heidensohn, 1995: XII). Esta es una de las cuestiones que los abordajes feministas de la criminología han ido debatiendo desde hace más de veinte años (y todavía siguen haciéndolo con nuevas aportaciones (ver Gelsthorpe, 2010; Burgess-Proctor, 2006; Chesney-Lind y Morash, 2013; Renzetti, 2013, entre otras).

En las investigaciones de todas estas autoras, se cuestionan y se analizan las causas de ese dominio androcéntrico en la criminología, así como las propias relaciones entre el feminismo y la criminología. También, las razones por las que las mujeres criminales fueron olvidadas durante tanto tiempo por esta disciplina; si todavía perduran los estereotipos positivistas sobre la delincuencia femenina o si se está construyendo un nuevo tipo de «mujer criminal y delin-

1. Este dominio anglosajón se debe a varias razones, de las que se destacan dos principales. Por un lado, el mayor desarrollo de la criminología en estos países, especialmente por su existencia como disciplina académica en las universidades de habla inglesa, y el auge de las perspectivas feministas en las ciencias sociales de dichos países. Y, por otro lado, las posibilidades de publicación y difusión que tienen, a nivel mundial, las investigaciones escritas en inglés y que versan sobre realidades de países anglosajones. Ello acaba discriminando a las investigadoras que escriben en otras lenguas y que proceden de otras zonas geográficas, como es el caso de Europa del Sur o de países de América Latina, que ven reducidas las oportunidades de difusión de sus trabajos y de sus ideas en favor de una cultura académica anglófila que sobrevalora lo que está escrito e investigado en inglés. Ver, al respecto, el artículo siguiente de este monográfico. 
cuente» con estereotipos más contemporáneos; las características y los perfiles de las mujeres encarceladas, sus delitos y sus condenas; el tipo de régimen y de tratamiento penitenciario que se aplica en las cárceles femeninas y las diferencias con el que se aplica a los hombres; el tipo de discriminaciones que existen y sus causas; el trato que la policía, los tribunales, sus jueces, los funcionarios de las cárceles, los trabajadores sociales y, en general, los profesionales del entramado penal y penitenciario dispensan a las mujeres; el papel que tienen las distintas entidades de la sociedad civil, sean las feministas, las de apoyo y denuncia, las religiosas en relación con las mujeres presas, y las diferentes formas que tienen las mujeres para rebelarse, usando las nociones dominantes de la identidad "femenina» para desafiar diferentes aspectos del régimen penal y penitenciario y desarrollar estrategias de resistencia (Bosworth, 1999).

Algunas veces, los estudios incluyen datos y estadísticas oficiales sobre los delitos y las cárceles de mujeres. Pero estos datos no son ni del todo fiables, ni suficientes, ya que, en general, como apuntan Heidensohn (1985), Genders y Player (1987) y otras autoras, solo dan una ligera pincelada acerca de los perfiles penales femeninos con unos pocos y sesgados datos de delitos y condenas. Por eso cobran gran importancia las voces de las mujeres presas, sus experiencias y etnografías de vida, sobre todo por la forma en que cuestionan y desaprueban los estereotipos de mujeres delincuentes que se construyen a partir de esas estadísticas. Aun así, muchos estudios destacan que el índice de encarcelamiento está creciendo mucho más que el índice de criminalidad femenina en casi todos los países de referencia de los estudios (Morris, 1987; Seear y Player, 1986; Gelsthorpe y Morris, 2002, en el Reino Unido, y Davis, 1996, en Estados Unidos, entre otros). A nivel internacional, sigue aumentando sobre todo por parte de mujeres que cometen delitos contra la propiedad «no violentos» y relacionados con el tráfico de drogas.

Esta «paradoja penal», como la denominan Gelsthorpe y Morris (2002), refleja la necesidad de forzar un cambio radical. Gran parte de las investigadoras abogan por desarrollar políticas penales alternativas, que cambien la dirección del endurecimiento de las sanciones penales a las mujeres - disminuyéndolas para reducir la población femenina en las cárceles- o directamente para abolirlas. Para este último caso, Davis (1996) propone un rol protagónico a las propias mujeres presas, para que ellas mismas se impliquen en el debate y propongan sus estrategias y alternativas. En sus obras, exploran posibilidades y proponen estrategias conjuntas entre la academia, los movimientos sociales y las personas que diseñan las políticas, para reducir la población penitenciaria, en general, y la femenina, en particular, $y$, finalmente, abolir el encarcelamiento femenino, que sería totalmente evitable y sin sentido (Carlen, 1998 y 1990).

Como puede verse, tal como constatan casi todos los estudios presentados y en conjunto, estas aportaciones efectúan críticas de los regímenes existentes dentro de las cárceles, pero además, especialmente y en el caso de las mujeres, cuestionan el hecho en sí del encarcelamiento y lo que el encierro comporta para ellas (Carlen, 1983, 1987 y 1990; Carlen et al., 1985; Heidensonh, 1985; Dobash et al., 1986). 
La «exclusión de la exclusión» es el perfil que sobresale cuando se estudia a las mujeres encarceladas en todos los países de referencia de las investigaciones. Porque muchas de ellas ya fueron "excluidas socialmente» antes de estar condenadas y, una vez ya están encerradas, la cárcel las vuelve a excluir con sus políticas de aprisionamiento y castigo. Historias de mujeres pobres, apartadas antes de entrar en el sistema de justicia criminal, descritas por medio de parámetros similares en todas las investigaciones: sin trabajo remunerado, con problemas de vivienda o sin hogar, miembros de grupos minoritarios, jóvenes, cabezas de familias monoparentales o con responsabilidades en el hogar y funciones domésticas mayormente asumidas por ellas desde muy jóvenes y que, a menudo, no controlan del todo. Tras la exclusión social que, en la gran mayoría de los casos, padecen antes de estar condenadas, la cárcel las vuelve a excluir con sus políticas de encierro, castigo y aislamiento. En las prisiones, ellas son condenadas a tratamientos y a programas penitenciarios que las «infantilizan, domestican, medicalizan y disciplinan», cuatro aspectos clave que serán ampliamente explicados, teorizados y contrastados empíricamente en la mayoría de todas estas investigaciones (ver también su exhaustivo análisis en Almeda, 1999, 2002 y 2003).

Obviamente, en todas las investigaciones, hay una dimensión clave y transversal que es el género. Sin embargo, las diferentes corrientes del feminismo socialista, lesbiano o negro han planteado la necesidad de integrar, en el movimiento y en la teoría feminista, realidades específicas de las diversas opresiones, posiciones jerárquicas y de dominación dentro del propio feminismo (Davis y Bhavnani, 2000; Bosworth y Carrabine, 2001; Burgess-Proctor, 2006; Bernard, 2012; Chesney-Lind y Morash, 2013, Ballesteros y Almeda, 2015). De esta manera, para estudiar la realidad penitenciaria y las mujeres presas, debe partirse de análisis interseccionales que reconozcan e incluyan, simultáneamente con el género, la clase social, la raza, la etnia, la nacionalidad, la sexualidad, la edad, la religión, la discapacidad u otras dimensiones que reflejan las múltiples posiciones que construyen la vida cotidiana y sus relaciones de poder.

\section{Cárceles de mujeres en el Estado español: primeros estudios de finales del siglo $\mathrm{XX}$}

Las instituciones femeninas de reclusión han tenido y tienen su propia historia, su propia filosofía, su propia lógica de funcionamiento y su propia fisonomía, porque, a lo largo de los siglos, ha habido una forma diferente de castigar a los hombres y a las mujeres que han vulnerado las leyes penales, y ello debe explicarse y documentarse históricamente (Almeda, 1999, 2002 y 2005b).

En el Estado español, el primer trabajo sistemático sobre la temática es el exhaustivo tratado penitenciario de 1608, realizado por la monja de Valladolid sor Magdalena de San Jerónimo, con el cual se pretendía «salvar a las mujeres que habían perdido el temor de Dios». Ello no es casual, ya que las primeras cárceles concebidas como tales y que existieron en muchos países fueron precisamente las femeninas, tal y como se demuestra para el caso de España con las casas galera promovidas por la monja vallisoletana. 
Hacia finales del siglo xix, destaca la famosa obra de Concepción Arenal El visitador del preso, donde ya se hacen importantes referencias críticas a las condiciones de encierro de las mujeres. Posteriormente, durante más de cuarenta años, la dictadura franquista impuso un férreo régimen cívico-militar que blindó cualquier atisbo de investigación sobre sus cerradas y represivas instituciones penitenciarias. Hacia finales del régimen (segundo lustro de los años setenta, coincidiendo no casualmente con el inicio de la nueva etapa política del Estado español), surgieron los primeros trabajos, precursores, de carácter histórico y testimonial, que fueron escritos primordialmente por mujeres que experimentaron, ellas mismas y/o sus familiares, la crueldad y la represión de las instituciones penitenciarias franquistas (entre otros, Pàmies, 1975; Dapena, 1978; Falcón, 1977; Doña, 1978). Luego, las cárceles femeninas y la situación de las mujeres encarceladas no serían objeto de estudio por parte de investigadoras ni de investigadores - con alguna excepción — hasta finales de la década de 1980.

Desde entonces, hay que distinguir dos etapas bien diferenciadas según la producción y la densidad de publicaciones, las disciplinas de procedencia de la mayoría de estudios o las temáticas tratadas en los trabajos. Una etapa inicial, que comienza en los años ochenta, y en la cual continúan los estudios históricos, pero ya empiezan a publicarse otro tipo de trabajos desde enfoques jurídico-criminológicos sobre la criminalidad femenina y sobre la situación que se vive, en general, en las cárceles de mujeres. Esta primera etapa se prorroga hasta principios del siglo XXI, cuando irrumpe con fuerza una segunda que se alarga hasta la actualidad y que es mucho más fecunda, ya que proliferan distintas investigaciones y estudios procedentes de diversas disciplinas - dentro de las que destaca la sociología, antes prácticamente inexistente en la temática.

En la primera etapa citada, continúan los precursores trabajos históricos sobre las cárceles femeninas de la dictadura franquista, que contienen enfoques críticos y denuncias acerca de la deplorable y terrible situación que vivían las mujeres presas en ese período, muchas veces contada por ellas mismas (Cuevas, 1982; Barranquero et al., 1994; véase también otras referencias similares citadas en Hernández, 2015). Pero también aparecen otros estudios históricos más academicistas sobre las cárceles en épocas anteriores, que hacen referencia explícita a las mujeres recluidas: un breve repaso a las galeras de mujeres de los siglos XVII y XVIII (Fiestas Loza, 1978); las cárceles de mujeres del siglo XVII (Barbeito, 1991); los presidios y casas de corrección del siglo XIX valenciano (Llorca Ortega, 1992); las casas de misericordia del siglo XviII en Barcelona (Carbonell, 1997); las de corrección del siglo XIx (Gutiérrez, 1997), y el excelente análisis de Telo Nuñez (1995) sobre la obra de Concepción Arenal y de Victoria Kent, dos juristas clave que hablaron, debatieron y pensaron acerca de políticas penitenciarias españolas específicas para las mujeres condenadas.

Acompañando a dichos estudios históricos, podemos ubicar, también en esta primera etapa, un conjunto de trabajos jurídicos y/o criminológicos bastante diversos. Por un lado, se trata de análisis teóricos realizados desde la academia, con perspectivas más bien sociojurídicas y que, en ciertas ocasiones, 
incluyen enfoques de género: Miralles (1983); Beristain y De la Cuesta (1989); Giménez-Salinas y Rifa (1992); Bodelón y Bergalli (1992); Herrera (1993); Larrauri (1994) o Bueno Arús (1995), entre otros. Dichos estudiosos focalizan en el análisis feminista del derecho y del papel que este tiene en la sociedad; en las relaciones entre el derecho penal, la criminología y las mujeres; en la evolución del derecho penal como instrumento de los poderosos o su reclamo por parte de colectivos de mujeres que lo reivindican como instrumento de liberación; en las causas de la delincuencia femenina, su bajo porcentaje en relación con los hombres y su vinculación a la diferente forma en que las mujeres son socializadas y sujetas desde pequeñas a controles informales más efectivos y mayores; y también hay algunas descripciones de las características de las cárceles femeninas y sus aspectos más discriminatorios. Por otro lado, se trata de reflexiones de profesionales del derecho, abogadas y/o jueces en ejercicio, que trabajan directamente con mujeres detenidas, condenadas o encarceladas. Exponen sus ideas, sus datos y sus experiencias en congresos nacionales y regionales organizados por sus mismos gremios o federaciones. En este caso, el enfoque sí que es claramente feminista y de crítica a las discriminaciones que padecen las mujeres en el sistema penal y penitenciario español (Bona, 1992 y 1994; Balmaseda y Carrera, 1995; Sepúlveda, 1995; Fernández et al., 1995). Entre otras cuestiones, señalan lagunas concretas de la regulación penal y penitenciaria española que provocan discriminaciones contra las mujeres encarceladas, vulneraciones a sus derechos y dificultades de acceso a la justicia. También apuntan problemas prácticos y cotidianos en el encierro penitenciario femenino; denuncian criterios de discriminación y discrecionalidad en la aplicación de las causas de «inadaptación» — siendo estos más rigurosos en el caso de las mujeres-, y plantean las medidas alternativas a la prisión específicas para mujeres. De esta forma, después de casi veinte años de inicio de la democracia en España, empiezan a describirse las múltiples carencias de los centros de reclusión femeninos, así como la falta de aplicación adecuada de la normativa penitenciaria que se impulsó al finalizar la dictadura.

También en este período hay otro grupo de estudios —-más reducido y heterogéneo que los anteriores - que comprende informes hechos por entidades de apoyo a mujeres privadas de libertad, así como algunas investigaciones empíricas más académicas o institucionales. Los primeros señalan problemáticas de las encarceladas, especialmente en relación con las carencias de programas de reinserción en el interior de los centros y las dificultades de mantener los vínculos familiares, reivindicando la necesidad de establecer cambios profundos en las cárceles y de desarrollar estrategias de resistencia por parte de ellas (Emakume Eta Justizia (Salhaketa), 1994; Grup Dona i Presó, 1995). Entre los segundos, destaca el extenso trabajo sociológico — confeccionado como un manual — de Andrés Canteras Murillo (1990), financiado por el Ministerio de Justicia, sobre la delincuencia femenina en España. En él, se analizan históricamente las teorías tradicionales sobre el delito y, específicamente, la delincuencia femenina - aunque pasando por alto las reflexiones de la criminología crítica y de la criminología feminista, ya en boga en muchos países del entorno- $y$ 
las estadísticas sobre su evolución en España (1975-1985). Más adelante, los primeros trabajos de Almeda estudiarán, desde un enfoque sociológico del control social de las mujeres, la perspectiva de las propias mujeres encarceladas y el reducido tejido asociativo que las apoyaba (Almeda, 1992 y 1994a). Pero todos estos estudios no serán referenciados ni articulados con los otros saberes científicos ni con los discursos políticos hasta el siglo siguiente. Encontramos también los análisis de dos psicólogas en ejercicio, Pi-Sunyer y Vendrell (1988 y 1992), sobre calidad de vida y maternidad en la cárcel de mujeres de Wad-Ras de Barcelona (con entrevistas a presas y con talleres participativos incluidos), mediante un enfoque bastante crítico de la situación que rescata las estrategias femeninas para afrontar las dificultades de las relaciones familiares. Enfoque bien diferente es el de Clemente (1987a y 1987b). Sus estudios tienen el mérito de incluir el fenómeno de la delincuencia femenina en sus obras y en sus análisis psicológicos, pero, a diferencia de las autoras anteriores, adopta un enfoque claramente tradicional sobre el tema, sin incorporar tampoco ninguna de las ideas de la criminología crítica y feminista, que cuestionaban las tesis positivistas que este autor, aunque con matices, sigue sosteniendo un siglo después. Dentro de este grupo, cabrían también los informes descriptivos de García Mas et al. (1987 y 1989), encargados por la Administración sobre la temática de las drogas, la cárcel y la delincuencia entre las mujeres jóvenes. Ambos cuentan con muchos datos estadísticos y con trabajo cualitativo de interés para empezar una primera aproximación al tema, pero sin suficiente sustento teórico ni marco criminológico ni sociológico.

En ese contexto, se produjo la investigación que concluyó con la tesis doctoral Passat i present de les presons de dones: Un estudi de cas al centre penitenciari de Brians, defendida en la Universidad Autónoma de Barcelona en el año 1999 (Almeda, 1999). Fue uno de los primeros análisis que estudió de manera sistemática las cárceles de mujeres en España. Más de cien citas de la comunidad académica la referencian como un punto de inflexión dentro de esta temática en España. Dicho trabajo denota la capacidad transformadora que pueden tener las sinergias de colaboración entre tres instancias que han sido claves en esa investigación: la acción militante y feminista comprometida desde el propio tejido sociocomunitario; la academia, y las administraciones y su funcionariado.

$\mathrm{Al}$ inicio, la investigación no tuvo un modelo teórico ni empírico sólido y cercano para fundamentar la estrategia metodológica del trabajo, por lo que se inició en esas condiciones - en soledad, sin experiencia y sin orientación- la exploración bibliográfica de los estudios que se habían llevado a cabo en España y a nivel internacional sobre los sistemas penales y las mujeres. Enseguida se pudo observar la falta casi total de referencias sociológicas sobre la temática en España, por lo que entonces se procuró ubicarse teóricamente construyendo el marco de referencia a partir de la criminología crítica feminista que existía en otros países, especialmente en los de tradición anglosajona. La criminología crítica feminista era la única que había tratado esta cuestión y que proporcionaba líneas teóricas para analizar el funcionamiento y la organización de las 
prisiones femeninas, así como las ideas y los discursos que las legitimaban. En realidad, son el contexto teórico de donde beben todas las investigaciones españolas realizadas a inicios del siglo XXI. Pero, a parte de la literatura, se tuvo también participación en entidades de apoyo a mujeres presas, como el grupo Dona i Presó, además de muchísimos intercambios con mujeres encarceladas y con profesionales del entramado penitenciario (personal de vigilancia y de tratamiento, abogadas, jueces, policías, etc.). Con las observaciones que se efectuaron, se comenzaron a exponer las primeras ideas en algunos de los eventos a los que se concurría, con el objeto de hacer las primeras contrastaciones con la comunidad académica (Almeda, 1992, 1994a, 1994b, 1996, 1997 y 1998). Paralelamente a esta primera etapa, también se quisieron indagar las razones por las que España tenía la tasa de encarcelamiento más alta de Europa, hecho que ni se sabía ni se estaba estudiando, ni siquiera se consideraba una cuestión relevante. Los factores explicativos principales que se fueron remarcando a lo largo del trabajo fueron los siguientes:

a) Precario desarrollo del estado del bienestar en España.

b) Largos e intensos procesos de feminización de la pobreza.

c) Falta de medidas sustitutivas y alternativas de la pena privativa de libertad.

d) Aumento de los delitos contra la salud pública entre la población reclusa femenina.

e) Nuevas políticas de endurecimiento de las sanciones penales, especialmente en aquellos delitos que las mujeres cometen con mayor frecuencia, particularmente las extranjeras.

f) Intensificación de los procesos de criminalización y discriminación de la extranjería en general, y de las mujeres extranjeras en particular.

g) Incremento significativo de los dispositivos de control punitivo-represivo institucionalizado.

h) Reducido desarrollo del tejido asociativo de apoyo a las mujeres encarceladas. (Almeda, 2001, 2002 y 2003; Almeda y Di Nella, 2011).

Después de esta primera fase/etapa de la tesis, se inició la segunda con un trabajo de campo en el que se escogió el módulo de mujeres del centro penitenciario de Brians (hoy Brians I), el penal de mujeres más importante de Cataluña (llamado a ser el modelo de referencia), por lo que se solicitaron los permisos respectivos de entrada a la prisión, que tardaron mucho en ser expedidos, a causa de lo cual la propuesta estuvo a punto de naufragar. Al cabo de más de un año de demora, llegó el aviso de que se podía comenzar el trabajo de campo. No había un plazo prescripto ni siquiera estaba previamente previsto. $\mathrm{Al}$ inicio, se trataba de ir solamente unos días, pero, al final, se asistió como investigadora "participante» durante casi nueve meses (de enero a septiembre de 1995). En ese lapso, se permaneció investigando más tiempo dentro de la cárcel que cualquier otro personal penitenciario, a pesar de no estar desempeñando ninguna de sus funciones. Las horas se pasaron deambulando y aprendiendo, primero, por los pasillos, las oficinas y los comedores con los funcionarios y las 
funcionarias del centro y, después, en los patios, en la biblioteca, en los espacios consignados para hacer las entrevistas y en las celdas con las mujeres presas. Entrevistando, conversando, escuchando, grabando, comiendo, fumando, riendo, emocionando, enrabiando, apuntando y mirando papeles. Se ingresó como la joven investigadora a quien observar de cerca, pero, después de unos cuantos meses, se acabó asumiendo una especie de no lugar, anónimo e indiferenciado. Fue entonces cuando el trabajo de campo in situ dio sus mayores y mejores frutos. Se acabó realizando 37 entrevistas en profundidad a mujeres penadas (la mayoría de ellas, entrevistadas tres veces), 10 al equipo directivo y 34 a todo el conjunto de profesionales que integraban los diferentes equipos de personal de la prisión de mujeres del centro. También se llevó a cabo un estudio exploratorio y cuantitativo de todo el material de archivo registrado — sin soporte tecnológico- en las oficinas de Régimen y Tratamiento de la misma prisión sobre la situación y las características de las mujeres ahí encerradas. Paralela y posteriormente, el trabajo en el centro se completó con entrevistas a abogados y abogadas penalistas y de derecho penitenciario, jueces de vigilancia penitenciaria y, nuevamente, a las entidades del tejido colectivo (de apoyo a presas, religiosas, de inserción social, etc.). Y, sobre todo, se completó mediante largas charlas con mujeres que cumplían su pena en regímenes extramuros, realizadas por las tardes noches o durante los fines de semana.

Una vez acabada la investigación empírica, se entró entonces en la «tercera fase» de la tesis, consistente en revisar el inmenso material que se había producido en las dos fases de investigación. Para ordenar la interpretación del material, se complementó el análisis desde la criminología del género que se estaba utilizando, situando y contextualizando sociohistóricamente la criminalidad femenina y las instituciones de encierro. Saliendo de los estrechos márgenes del estudio de caso de Brians y sus muros carcelarios, se tomó distancia fáctica y también simbólicamente de esa prisión, para poder captarla en toda su complejidad. En realidad, ya se había indagado sobre la historia del castigo y del encierro femenino en el análisis bibliográfico que se había efectuado, pero hacía falta retomarla entonces como historia viva, sociológicamente relevante, para reinterpretar el estudio de caso y el conjunto de cárceles de mujeres. Así, la estructura de redacción de la tesis doctoral fue iniciada con el abordaje sociohistórico, desde las casas galera y las casas de misericordia del siglo XVII hasta las cárceles femeninas de la dictadura franquista, todas ellas analizadas en el marco de la historia de las ideas punitivas del momento correspondiente. En la segunda parte del texto, se muestran las cárceles de mujeres durante los primeros veinte años de democracia, en el contexto descriptivo de todas las prisiones. Y, finalmente, en la tercera parte, se presenta el estudio de caso de la cárcel de mujeres de Brians, analizando a fondo la institución, la población femenina que se encuentra reclusa en ella comparada con la población reclusa masculina, las mujeres de Brians entrevistadas, el personal penitenciario entrevistado, las familias de las mujeres presas y las políticas penitenciarias del centro. Las conclusiones de la tesis ya han sido vertidas en diversas publicaciones, por lo que no serán reproducidas aquí (ver Almeda, 1999, 2002, 2003 y 2005a). El 
proceso de investigación y publicación duró más de diez años. Al cabo de este período, fue necesario relacionar todos los datos, los papeles, los protocolos, los discursos, las experiencias, las entrevistas, las ponencias, las historias, los documentos oficiales, los libros y los artículos leídos, así como las ideas y las reflexiones recopiladas para ir construyendo, en el marco del doctorado, un modelo propio, teórico, metodológico e interpretativo de las cárceles de mujeres y de las mujeres encarceladas. Era la primera vez, y ha sido la última hasta el momento, que una investigadora, sin estar situada biográficamente como presa o ex-presa, ni tratada como personal penitenciario ni de apoyo a mujeres presas, entraba en una cárcel del Estado español para elaborar un trabajo de campo de tan larga duración y con tanta intensidad y pluralidad metodológica.

Todo este conjunto de informes, estudios, investigaciones, manuales y ponencias sobre la delincuencia y la ejecución penal femenina conformarían esta "primera etapa» de análisis sobre dicho ámbito en el Estado español. Conforman el material que tenemos disponible de esa época y, obviamente, han tenido cierta incidencia en las investigaciones que se han ido desarrollando posteriormente, en los últimos quince años. Seleccionados por separado, son de gran interés y valor, porque aportan nuevas reflexiones, ideas y datos. Sin embargo, en conjunto, se trata de pocos trabajos e investigaciones y, además, están muy dispersos entre ellos, puesto que no tienen ningún hilo conductor que trence continuidades entre las investigaciones. La gran mayoría no están enmarcados en ninguna perspectiva teórica, no beben de ninguna de las fuentes bibliográficas mencionadas anteriormente, ni citan o referencian a la criminología feminista comentada ni a sus muy diversas autoras y publicaciones, tan relevantes - ya para esta época- de la criminología a nivel internacional. Algunos análisis hacen referencia a las discriminaciones que padecen las mujeres bajo medidas de control penal y, especialmente, las que están privadas de libertad. Incluso abordan ciertos aspectos propios de una perspectiva de género, pero no se argumenta teóricamente para sostenerlas o no se contrasta la teoría con la realidad observada. Así es que, con la excepción de la investigación doctoral recién reseñada, los trabajos señalados no acaban de ahondar a fondo en las realidades de las cárceles femeninas y sus especificidades. Muestran la escasa producción académica realizada en este ámbito y el prácticamente nulo interés por estas instituciones totales femeninas por parte de las ciencias sociales en general y, especialmente, de la sociología. Pero, con ello, se puede observar mucho más. La forma que tiene una sociedad de castigar y sancionar a personas que vulneran las leyes penales refleja en gran medida cómo es esa sociedad, qué tipo de control social se ejerce, cómo se ejerce y quién lo ejerce. Los delitos que son castigados y los que no, sus causas, sus orígenes, la relación con la desigualdad, el conflicto social, la pobreza, la exclusión, el género, la clase social, los grupos étnicos, la extranjería, todos ellos son temas y aspectos que la sociología y otras disciplinas deberían analizar y en las que se tendría que profundizar. Sin embargo, en la agenda española de estas disciplinas, no figuraba dicha temática. Las cárceles de mujeres fueron casi invisibles para los estudios sociales del último cuarto del siglo xx en España. Se estaba muy lejos 
todavía de consolidar una corriente crítica y feminista sobre esta cuestión, pero, paradójicamente y sobre todo con ello, se desencriptaba el rol encubridor que representa tal omisión de nuestras ciencias sociales, de la reproducción de las desigualdades colectivas de las que son víctimas las mujeres más vulnerables de nuestra sociedad.

\section{Investigaciones sobre cárceles de mujeres en España desde comienzos del siglo XXI}

A partir del año 2000, las investigadoras y las investigaciones sobre cárceles de mujeres en España han crecido incesantemente. Abundan los enfoques más generalistas, que ofrecen una primera radiografía de la situación de estas instituciones y de las realidades de las mujeres encarceladas, pero también deben y pueden considerarse otros abordajes.

El hecho de ser mujer extranjera (especialmente cuando se es «extracomunitaria»), mujer de una comunidad gitana, haber sufrido violencia machista o haber tenido y/o tener adicciones a ciertas sustancias psicotrópicas son, de hecho, temas o ejes transversales que podrían añadirse a la decena de particularidades mencionadas, pero no como especificidades, sino como filtros, como «coladores» que ayudan a definir y a explicar mejor las situaciones, problemáticas y perfiles de los diversos colectivos de mujeres encarceladas. (Almeda y Di Nella, 2011:36-37)

En un trabajo de esta naturaleza, no es factible referenciar todo lo que se ha escrito sobre ello en España en los tres últimos lustros (sería temerario y empobrecedor intentar hacerlo). Por ello, seguidamente, se hace un inventario de varias de las principales aportaciones realizadas en este campo, en muchos casos con breves menciones que habilitan a sus análisis pormenorizados en futuros artículos o directamente en la fuente primaria a la que se hace referencia.

A principios del siglo XXI y hasta el presente, los estudios históricos sobre las cárceles de mujeres han continuado, perfilándose ya como una línea de trabajo constante que sigue produciendo y ampliando autores como Vinyes (2000 y 2002), Hernández (2003, 2013 y 2015) o Martínez (2002), entre otros.

Desde los abordajes sociológicos, destacan los estudios de Miranda (2002) y los de Manzanos y Balmaseda (2003), que tienen trabajos de campo extensos y sólidos, referencia de muchos de los que se hicieron posteriormente, y que inauguran de alguna manera lo que denominé anteriormente la «segunda etapa» en la evolución de las investigaciones sobre ejecución penal femenina en España. María Jesús Miranda y Rosemary Barberet llevaron a cabo, en el año 1998, la primera investigación con financiamiento del Instituto de la Mujer sobre las necesidades y las demandas de las mujeres presas en España. El objetivo era analizar la eficacia y la adecuación de las políticas a las necesidades y a los intereses de las mujeres encarceladas, especialmente a partir de una encuesta a 365 internas de 28 centros penitenciarios del país, con un amplio abanico de temas como la vida cotidiana, los estudios, el trabajo, la familia, los malos 
tratos, las drogas o la asistencia sanitaria, entre otros. También se incluyeron grupos de discusión con distintos perfiles femeninos, entrevistas con funcionarios penitenciarios y también un estudio con datos secundarios de la evolución de la población reclusa femenina y sus características básicas. De toda esta extensa investigación, es muy poco lo que se ha explotado y publicado. Hay un artículo en el que se explica la metodología y se ofrecen algunos resultados de la realidad de las mujeres encarceladas, con muchos datos secundarios y también información acerca de las políticas penitenciarias principales (Miranda, 2002). Sin embargo, en él no aparecen contextualizadas las reflexiones o la presentación de la investigación en sí. Básicamente, se trata de un trabajo descriptivo y poco crítico con la situación penitenciaria de las mujeres, especialmente en relación con los resultados a los que llegaban otros análisis. Por su parte, el estudio de Manzanos y Balmaseda (2003) es un trabajo impulsado por la comisión de mujeres del Colegio de Abogados de Vizcaya y financiado por el Gobierno Vasco. Se basa en una extensa investigación sociológica que contó con una encuesta por cuestionario a las 78 mujeres encarceladas en las prisiones de Nanclares de la Oca (64) y Martutene (14). A diferencia del trabajo anterior, este denuncia claramente las malas condiciones de vida de las mujeres encarceladas, de quienes recoge varios aspectos: las características sociodemográficas, la situación penal y sanitaria, la maternidad, las condiciones materiales de los centros y las necesidades y las problemáticas más relevantes que presentan. Acaba el estudio con diversas propuestas de actuación y recursos para los centros de detención femeninos: una unidad para madres, otra de psiquiatría y una enfermería especializada (Manzanos y Balmaseda, 2003).

Respecto de las investigaciones sobre comunidad gitana, extranjería, drogas y violencias, un estudio señero que ha marcado un hito en las investigaciones sobre mujeres presas es el del Equipo Barañi (2001). Tratando el tema desde una perspectiva crítica y feminista, este excelente trabajo de investigación cualitativa y cuantitativa fue dirigido por María Naredo y Daniel Wagman y partía de la sobrerrepresentación del colectivo de mujeres gitanas en las cárceles del Estado español. El objetivo era analizar los distintos procesos de criminalización que padece el colectivo gitano en la sociedad española y las dinámicas discriminatorias de las instituciones del sistema penal, especialmente si son mujeres. Pocos años más tarde, la abogada Naredo publicaría otro estudio sobre el tema de las mujeres gitanas en centros penitenciarios, pero ampliándolo también a la problemática de las extranjeras encarceladas, que conformaban entre el 30 y el $40 \%$ del total del colectivo femenino que se encontraba en prisión en este estado (Naredo, 2004). El trabajo de Naredo inauguró, así, el tema de las mujeres extranjeras encarceladas como uno de los de mayor desarrollo de este período, siguiéndole diversas investigaciones (Martín, Miranda y Vega, 2005; Ribas, Almeda y Bodelón, 2005; Almeda, 2010; Almeda y Di Nella, 2011; Castillo y Ruiz, 2006 y 2010, entre otros). En todas, se pone de manifiesto, entre otras muchas cuestiones, que las extranjeras todavía padecen más vulneraciones de derechos y más discriminaciones que las españolas, tanto durante el proceso penal como en el propio contexto penitenciario. Los 
enfoques interseccionales y decoloniales permiten profundizar en el tema y ver la mayor severidad punitiva y penitenciaria sobre las presas no nacionales, no europeas, a partir de clasificaciones y/o de categorías estereotipadamente racistas que las discriminan y las criminalizan aún más. Esta intensificación es, junto con el tráfico de sustancias psicotrópicas de uso o consumo prohibido por las autoridades sanitarias, uno de los factores clave para explicar el aumento de las tasas de encarcelamiento femenino en este país (Almeda, 2009; Almeda, Di Nella y Navarro, 2012). En el lucrativo mercado internacional de las drogas, las extranjeras representan el eslabón más visible, débil y proclive a la criminalización de la gran cadena del narcotráfico. Ellas ejercen de correos y de mulas (las mujeres que llevan la droga en el interior de su cuerpo y/o en sus equipajes), y serán fácilmente perseguidas, judicializadas y más castigadas (mayormente condenadas por delitos contra la salud pública a no menos de seis años de prisión).

Un tema que sale en muchas de las investigaciones citadas — aunque no con un abordaje monográfico integral — es la violencia machista y los abusos sexuales que muchas mujeres encarceladas han sufrido antes de su ingreso en prisión. Los estudios que están empezando a profundizar en ello son los de Cruells et al. (2005), SURT (2008), Roig (2012) o el de Fontanil et al. (2013), que, además, proponen medidas específicas para su tratamiento durante el encarcelamiento femenino y también al finalizar su condena.

Asimismo, en prácticamente todos los estudios mencionados en este artículo, se hacen referencias explícitas a la situación familiar y a la maternidad de las mujeres encarceladas. Entre los análisis monográficos que conviene citar, están los de la autora de este artículo (Almeda, 2005c), además de los de Naredo (2007), Igareda (2009) y Gea et al. (2014). Las mujeres presas sufren intensamente la ruptura de los lazos afectivos con sus hijas y sus hijos. La situación doméstica y el recurso de la familia representa un punto de intersección, por un lado, de influencia y apoyo positivo, pero, al mismo tiempo, genera ambivalencia y es algo incierto, porque, a menudo, el apoyo de la pareja es una promesa rota y se vive con gran dolor la separación de sus hijos e hijas; una pérdida real y simbólica, una «historia interrumpida». En muchas ocasiones, el apego a las criaturas propias se exacerba por la marginación, la soledad y el encierro, y las presas de culpabilizan de todo lo que no pudieron o no supieron hacer. La tesis doctoral de De Miguel (2016), por su parte, focaliza en las relaciones amorosas de las mujeres encarceladas y en sus afectividades como una forma de resistencia a esta marginación. Basadas en la necesidad de evitar dicha ruptura sociovincular, muchas investigadoras plantean directamente la búsqueda de posibilidades alternativas a la privación femenina de libertad y la necesidad de repensar la pena de prisión desde una perspectiva que permita que los colectivos de mujeres más vulnerables salgan del espiral de condena, marginación y estigmatización.

Por su parte, han continuado desarrollándose los estudios jurídicos y/o criminológicos sobre las cárceles femeninas y sus mujeres privadas de libertad. En el estudio de Cervello, de la Universidad de Valencia (2006), se hace una 
breve reseña histórica de la legislación penitenciaria, analizando la situación discriminatoria de las mujeres presas en España. María Acale, de la Universidad de Cádiz, ha trabajado mucho sobre la discriminación femenina por razón de género en el código penal. Tiene, entre otros, un estudio cuantitativo específico sobre las cárceles de mujeres (Acale, 2011), en donde analiza la variable género en lo que se denomina «victimización primaria y secundaria». En el trabajo realizado por el potente grupo de investigación del Instituto de Criminología de la Universidad de Sevilla sobre las realidades de las cárceles de mujeres en Andalucía (Mapelli Caffarena et al., 2012), se teoriza y se explica exhaustivamente esta realidad desde una perspectiva criminológica de género, recomendando aplicar medidas concretas de tratamiento y reclusión de mujeres que cuestionan críticamente la institución y la política penitenciaria actual.

Desde el campo de la pedagogía y la educación social, el libro coordinado por Fanny Añaños (2010), de la Universidad de Granada, constituye el primer trabajo sistemático sobre educación social en el contexto de las prisiones femeninas. Muchas de las aportaciones cuestionan directamente la factibilidad de las prisiones como espacio educativo. Otras indagan sobre si el proceso docente intramuros es —y/o debe ser - diferente en función del sexo. Además, se analiza, entre otras cuestiones, la importancia del trabajo social educativo dentro de las cárceles de mujeres, como paliativo de los efectos de asocialización y desculturación que esta produce, además de la profesionalización de la actuación socioeducativa frente a las asociaciones y a las órdenes religiosas que todavía acaparan muchos de los programas socioeducativos en las cárceles de mujeres. También cabe mencionar el monográfico específico sobre dicha temática en la revista de pedagogía social (Añaños y Yagüe, 2013) y la última publicación de Añaños con Jiménez (2016), en la que se aporta una ambiciosa investigación cuantitativa comparada sobre la realidad de la población presa a nivel internacional en Europa y América, focalizándose después en España y en la población femenina encarcelada. En conjunto, estos trabajos demuestran la ineficacia de las acciones «educativas» del sistema penitenciario español, especialmente de las que se están implementando actualmente para la «reinserción» de este colectivo.

Desde un enfoque más crítico e interdisciplinario —y quizás menos academicista que los anteriores - cabe destacar la breve pero radicalmente feminista aportación y reflexión sobre las mujeres encarceladas de Elixabete Imaz (2007), politóloga y antropóloga de la Universidad del País Vasco. En él, comenta como la invisibilidad es una de las violencias institucionales específicas que sufren las presas. Y también sostiene que, a menudo, se las estereotipa bajo perfiles etnocéntricos y paternalistas que las representan exclusivamente como víctimas. El enfoque victimista niega su derecho a ser vistas como sujetos capaces de decidir, personas que actúan, en determinado momento, con los recursos y las opciones que tienen a su alcance: «despliegan estrategias: de supervivencia, migratorias, etc. Saben que corren riesgos, aunque a menudo ignoran la magnitud del castigo que el "delito" supone, además de desconocer cómo funciona el sistema penal y la propia cárcel» (Imaz, 2007: 194). 
Desde otros trabajos producidos más colectivamente, cabe referenciar los estudios cualitativos y participativos de entidades de apoyo y atención a personas presas en el País Vasco, como los de la Asociación Zubiko —creada en el año 2002 a partir de la antigua Salhaketa Bizkaia, que contaba con más de 20 años de experiencia en la ayuda a personas presas - , sobre los efectos del encarcelamiento en mujeres y hombres presos y su entorno familiar (Aróstegi et al., 2008). También el que recoge las voces de mujeres presas en la cárcel de Pamplona, además de Salhaketa de esa ciudad (Frances y Serrano, 2011), en los que han participado académicas feministas de equipos interdisciplinarios de juristas, trabajadoras sociales y sociólogas.

Añadiendo la perspectiva comparada europea, cabe mencionar el proyecto Women, Integration and Prison: An analysis of the processes of sociolabour integration of women prisoners in Europe (2002-2005)-Proyecto MIP, un trabajo mixto entre diversas académicas y académicos europeos y SURT, como entidad de apoyo a mujeres en situación de exclusión social y coordinadora de la investigación. El proyecto se desarrolló durante dos años en Alemania, Francia, Inglaterra, España, Italia y Hungría y fue el primer estudio comparado sobre cárceles femeninas que incluía a las españolas. Tuvo como principal objetivo analizar desde una perspectiva de género la realidad de las mujeres en las prisiones femeninas y su vida tras la prisión, con un estudio especial acerca de la eficiencia de las políticas sociales y penitenciarias dirigidas a la integración sociolaboral de estas mujeres en cada uno de los países participantes (European Comission, 2006; Cruells e Igareda, 2006).

En la misma línea anterior de impulsar proyectos, investigaciones y encuentros transfronterizos, destaca el taller internacional titulado «Mujer y ejecución penal: Diagnósticos y alternativas», que se organizó en el Instituto Internacional de Sociología Jurídica de Oñati, cuyo resultado final fue el libro Mujeres y castigo, que recopiló todas las exposiciones que se realizaron en el evento (Almeda y Bodelón, 2007). El trabajo fue el fruto de diversos intercambios académicos y personales, que gestó una red internacional sobre género y sistema penal, básicamente de mujeres interesadas en explicar la historia y la realidad de las prisiones femeninas en España, México y Holanda. Desde una mirada crítica y feminista, el trabajo permite considerar que la situación de las mujeres presas era - y es - no únicamente un caso particular para los estudios sociojurídicos y de género, sino un elemento central para poder reflexionar sobre las contradicciones del sistema penal y penitenciario, así como sobre la defensa de los derechos de las mujeres (Almeda y Bodelón, 2007).

\section{Producciones institucionales en el nuevo contexto político y normativo de lo penitenciario femenino español}

En el contexto de este creciente interés y aumento de la producción científica sobre la ejecución penal femenina, en la primera década del siglo Xxi, se estaba fraguando también un nuevo proceso político y normativo sobre dicha temática. Con la llegada del socialismo obrero español al gobierno en el año 2004 y 
la incorporación como titular de la Dirección General de Instituciones Penitenciarias de la entonces diputada Mercedes Gallizo, comienzan a producirse algunos cambios en el abordaje general de la realidad carcelaria: la potenciación de ciertos programas de tratamiento; el impulso del cumplimiento de las penas en régimen abierto; el refuerzo de las relaciones con las entidades colaboradoras, y especialmente relevante para el tema aquí bajo estudio, el impulso del Programa de Acciones para la Igualdad entre Mujeres y Hombres en el Ámbito Penitenciario Español, aprobado en noviembre de 2008.

El programa nace del compromiso de la Secretaría General (SGIP) de elaborar y ejecutar un ambicioso proyecto para fomentar la plena igualdad en su campo de responsabilidad. Igualdad que se traduce en atajar aquellas situaciones y circunstancias que perpetúan, aún hoy en día, un trato discriminatorio de las mujeres en la ejecución penitenciaria, pero sobre todo, contribuir a romper las barreras sociales y personales que pudieren dificultar una adecuada inserción social y el pleno ejercicio de sus derechos de ciudadanía. (Dirección General de Instituciones Penitenciarias, 2009a: 27)

Un año después (el 14 de mayo del año 2009), se crea el Observatorio del Programa, para «el seguimiento de la situación de las mujeres en el ámbito penitenciario, siempre desde la perspectiva de género" (Dirección General de Instituciones Penitenciarias, 2009b: 3). Junto con ello, se desarrollan normativas internacionales, como la Resolución del año 2008 del Parlamento Europeo sobre la situación especial de mujeres en los centros penitenciarios, o las Reglas de Bangkok del año 2011, de Naciones Unidas, para el tratamiento de las reclusas. La perspectiva de género queda así instalada en el marco jurídico penitenciario español, al menos en lo que concierne a los programas y a las directrices generales de las políticas gubernamentales.

En este marco político institucional, cabe comentar la práctica profesional desarrollada principalmente desde el centro penitenciario femenino de Alcalá de Guadaíra por parte de la psicóloga Concepción Yagüe, que acabaría cristalizándose en varias publicaciones de diversa índole (2002, 2006a, 2006b, 2007, 2011, 2012 y 2014). Probablemente por la pertenencia de la autora al funcionariado y al personal jerárquico penitenciario (que no suelen exponerse con este tipo de producciones), esos trabajos han tenido una gran influencia institucional y académica. En efecto, Yagüe fue la directora de esta cárcel de Sevilla durante más de quince años (desde que el centro se creó en 1991) y subdirectora general de Tratamiento y Gestión Penitenciara entre 2008 y 2011, período en el que escribe algunas publicaciones específicas relativas a su mandato (Yagüe, 2012 y 2014). También hay enfoques más generales (Yagüe, 2002, 2006a y 2007), en los que facilita muchos datos de gran interés y que, a menudo, son difíciles de obtener respecto a todos los años. En estos trabajos, se explica que las mujeres están discriminadas también en la prisión. La realidad de las madres encarceladas con sus hijas e hijos es otro de los temas investigados por Yagüe. De atención prioritaria en el programa socialista mencionado, la exdirectora ha hecho una de las investigaciones pioneras sobre este tema en 
las cárceles españolas (2006b y 2011). También enumera algunos factores de discriminación, como son la lejanía de los centros, las peores condiciones arquitectónicas, los menores recursos humanos o las dificultades de clasificación (Yagüe, 2002, 2006a y 2007). Siempre destaca en sus estudios las «carencias», las necesidades y las demandas de las mujeres presas:

La temprana exposición a modelos delincuenciales provoca una adquisición de valores asociales donde la fuente de ingresos no pasa por el sacrificio, ni el esfuerzo personal. La subsistencia se encomienda al azar o a los servicios sociales. Las gratificaciones han de ser inmediatas. La ambición y la envidia hacia el éxito fácil están muy presentes. (Yagüe, 2006a: 6)

Poniendo a su centro como referencia para tratar de suplir estas carencias, lo importante será desarrollar políticas penitenciarias con perspectiva de género, que tengan en cuenta las características, las necesidades y las demandas de las mujeres encarceladas mediante medidas específicas para ellas «[...] que permitan a estas mujeres una mejora en sus capacidades personales y les ayuden a ejercer plenamente sus derechos de ciudadanía» (Yagüe, 2007: 1). Esta es, en efecto, una de las pocas cárceles de mujeres de España en las que ha habido un esfuerzo institucional para intentar mejorar las condiciones de encarcelamiento de esas mujeres "condenadas a la desigualdad» (título del último libro en el que Yagüe participa, 2012). Sin embargo, dichos trabajos no están enmarcados teóricamente, ni traen novedad reflexiva. Son aportaciones más bien descriptivas y poco críticas, sesgadas a favor de la política institucional por la cual se trabajaba. Sin siquiera dimensionar esta realidad del Estado español desde ningún tipo de perspectiva comparada, no se interpretan razones ni contextos destacables más allá de las conductuales de las propias mujeres encarceladas.

Otro de los aspectos muy estudiados y desarrollados se relaciona con la producción y el análisis de los datos cuantitativos sobre mujeres presas producidos por las instituciones penitenciarias, así como las razones que explican las tasas de encarcelamiento femenino en España (actualmente, el porcentaje de mujeres presas en este país es casi del $8 \%$ del total de personas reclusas, mientras el promedio europeo sigue sin llegar al 6\% (Council of Europe, 2015). La proporción española solo es superada por algunos pocos países, como Estados Unidos o Ecuador, que llegan casi al 10\% de mujeres presas (Añaños y Jiménez, 2016: 68). Ahora bien, en los estudios cuantitativos, lo que es más importante es la forma en que se obtienen y después se presentan los datos y los indicadores. Si se obtienen y/o se construyen con patrones androcéntricos, es muy difícil poder diseñar después políticas que estén acordes con sus necesidades. Si quiere convertir la posibilidad técnica de la producción de datos no androcéntricos en una realidad científica, debe haber además la voluntad política (también académica e incluso social) para explotarlos de esa manera y, sobre todo, después querer publicarlos (Almeda et al., 2014: 209). En esa dirección, cabe mencionar otras iniciativas de estudios cuantitativos y construcción de indicadores, como las del equipo de investigación de la UNED 
que lideró Viedma en 2012. Realizados a instancia de la propia administración penitenciaria de España, tuvieron gran acogida institucional para la divulgación de sus resultados en conferencias, foros, radios y medios de los más diversos. Probablemente, el enclave institucional de la iniciativa en general y de una de las autoras en particular así lo ha favorecido. Los mismos investigadores lo confirman: «sin la implicación de la propia Secretaría General de Instituciones Penitenciarias, el trabajo hubiera resultado imposible de concluir. Esta institución quería conocer los efectos de sus políticas de igualdad, el modo en que cada centro las ponía en marcha y el grado de cumplimiento de cada centro de un modo objetivo» (Del Val-Cid, Viedma-Rojas y Reviriego-Picón, 2013:33). La investigación seleccionó a 45 centros de reclusión de mujeres de España (de los 68 en total, no incluyendo a Cataluña, que tiene otra administración) con un mínimo de diez mujeres presas, y utilizó los datos de registros oficiales de cada uno de los centros, que es la información producida por los propios centros - fuentes secundarias - para controlar su actividad y la de las personas presas. También se incluyó un cuestionario con los datos que los centros debían ofrecer, varias entrevistas en profundidad y grupos de discusión (Del Val-Cid, Viedma-Rojas y Reviriego-Picón, 2013:31). El trabajo presenta las principales variables sociodemográficas, sociológicas, penales y penitenciarias, poniendo empíricamente de manifiesto las desigualdades y las discriminaciones de género que se reproducen en las diferentes facetas del encarcelamiento femenino respecto del masculino. También propone el Sistema de Indicadores de Discriminación en Instituciones Penitenciarias (SINDISCRIP), para observar la posible existencia de discriminaciones entre hombres y mujeres en los distintos centros penitenciarios españoles.

En diversos análisis de otro equipo de investigación que incluían manipulación de datos con fines estadísticos ${ }^{2}$, constatamos que, en los trabajos, ni las variables estudiadas están lo bastante desglosadas por sexos, ni hay ninguna variable que recoja especialmente la situación descrita desde la mujer encarcelada. Esto pasa en los datos catalanes del Departamento de Justicia de la Generalitat de Catalunya, en los españoles de la Secretaria General de Instituciones Penitenciarias del Ministerio del Interior de España y en los europeos del Consejo de Europa, las tres fuentes básicas — y prácticamente únicas - de donde se extraen las estadísticas en referencia a estos tres territorios. Por ello, lo que cabe destacar de la perspectiva no androcéntrica en relación con los indicadores son sus dos grandes vertientes o concreciones: primero, que todas las variables estudiadas estén desglosadas por sexos (indicadores de igualdad de género) y, segundo, que se incluyan también variables que recojan experiencias y rasgos propios de las mujeres (indicadores desde la experiencia femenina), que son los que, en mayor medida, reflejan las discriminaciones respecto a las presas.

2. Además del exhaustivo trabajo cuantitativo realizado en la tesis doctoral ya citada, me refiero a la manipulación de datos con fines estadísticos desarrollada principalmente desde el Grupo Interuniversitario Copolis en más de una decena de sus proyectos de investigación. En ese marco, se ha trabajado con diversas bases de datos de alcance local, nacional o internacional. 
Por otra parte, y relacionado con los estudios cuantitativos, cabe añadir también que una parte significativa de los abordajes feministas de la criminalidad y del control punitivo de las mujeres empieza sus estudios comentando su poca participación en la comisión de delitos que acaban con pena de cárcel, por lo que es esgrimida como una de las razones principales para justificar la «invisibilidad de las mujeres presas» en la literatura criminológica en general. Para Dolores Juliano (antropóloga argentina radicada hace muchos años en Cataluña, que analiza el delito y la transgresión femenina), es paradojal que las mujeres, como colectivo socialmente más pobre y vulnerable a la exclusión a nivel mundial, sea el que cometa menos delitos - y menos aún asociados a las necesidades económicas-. En uno de sus libros (Juliano, 2011), argumenta que las posibles respuestas están vinculadas al hecho de que las mujeres desarrollan otras estrategias de supervivencia, como la formación y el estudio, la construcción de redes de apoyo, el trabajo en la economía sumergida o el trabajo sexual.

Delinquir sería, en ese sentido, la peor de las opciones posibles, por lo que la cárcel rompe el vínculo familiar, y es por eso que las mujeres delinquen menos. Igualmente, nos cuenta cómo ellas viven las normas y cómo son evaluadas cuando las incumplen, de qué clase de riesgos consideran prioritario defenderse, qué estigmatizaciones se resignan a aceptar y qué recursos utilizan para esquivar lo que consideran que son sus peores posibilidades.

\section{Reflexiones finales}

Los estudios y las autoras y los autores mencionados a lo largo de este artículo demuestran que, en el Estado español, existe una línea de investigación crítica y feminista sobre la ejecución penal femenina, en especial sobre las cárceles de mujeres, que se está consolidando desde principios del siglo XxI. Se trata de trabajos interdisciplinarios desde la sociología, la historia, la antropología, la criminología, la psicología, el derecho penal, la educación social o el trabajo social, con abordajes predominantemente no androcéntricos que radiografían las prisiones de mujeres y las realidades de las que están encarceladas. Son estudios panorámicos o focalizados en aspectos y en temáticas que necesitan mayor profundización. Si bien parece que estén dispersos, empieza a existir una sistematización que se ha querido reflejar en este artículo. Poco a poco, pero sin pausa, se ha ido tejiendo un hilo conductor común entre las investigaciones, muestra de que sus autoras intercambiaron reflexiones y se leyeron mutuamente. Algunas, las empezamos con largas tesis doctorales, otras con estudios por encargo o fruto de investigaciones nacionales o europeas financiadas; las hay más institucionales realizadas con los propios medios de los profesionales del sistema penal que plasman sus experiencias y sus saberes en publicaciones de referencia, o las de entidades feministas y activistas sin medios, pero con investigaciones participativas de gran calidad. Todas ellas van perfilando un abanico de datos, reflexiones y voces de mujeres presas, y también de personal del entramado penal y penitenciario que las rodea, que va llenando el vacío de 
saberes que había en la academia y en la política penitenciaria, también falta de estudios.

Muchas hemos partido y nos hemos basado en las reflexiones que ya hicieron nuestras antecesoras, criminólogas y sociólogas críticas y feministas de la tradición anglosajona - si bien también nos influyeron las pioneras latinoamericanas-, tratando de alimentar un diálogo intergeneracional, multicolor y multidisciplinario para el avance de esta área de conocimiento, por entonces todavía muy poco difundida dentro de la sociología o de la criminología española.

Cierto es que, finalmente, nuestras reflexiones, propuestas y planteamientos críticos y feministas no han sido promovidos. Ni lo fueron entonces, ni tampoco ahora en el siglo XXI. No es esta la tendencia actual. Pese a los intentos de cambio, no hay grandes transformaciones. En España, el Programa de Acciones para la Igualdad en el Ámbito Penitenciario Español terminó su vigencia en 2011, coincidiendo con la deriva de los últimos tiempos del gobierno socialista y la victoria del nuevo gobierno del Partido Popular. Aunque algunas de las medidas continuaron en marcha, se produjo una parálisis en la incorporación de esas acciones para la igualdad, así como una clara desviación de la atención que, durante un cierto tiempo, recayó sobre las mujeres encarceladas (Ballesteros y Almeda, 2015). Con todo, hay que estar igualmente alerta a esas "perspectivas de género" que encriptan la reproducción de las discriminaciones de las mujeres presas. Como comentan Mapelli Caffarena y sus colegas:

Se trata de evitar que, como se denuncia en medios criminológicos comparados, la consigna de la sensibilidad institucional al género se convierta en un fraude de etiquetas que encubre nuevas y artificiosas fórmulas - como la llamada terapunición - de legitimar la prisionalización de prisioneras sociales. (Mapelli Caffarena et al., 2013: 94)

En las cárceles españolas, al igual que en las francesas, italianas y británicas, se sigue repitiendo la misma historia: escaso número de prisiones exclusivamente femeninas; ubicación de estas fuera de los centros urbanos principales del país, lo que dificulta que los familiares puedan acceder a ellas; distribución de muchas mujeres en pequeñas secciones penitenciarias dentro de cárceles de hombres que no reúnen las condiciones suficientes; aislamiento de muchas presas que no reciben visitas familiares; excesivo alcance del ejercicio del poder con disciplina abusiva con contenido anodino de la mayoría de las faltas disciplinarias; cumplimiento irregular e ilegal — con períodos largos de aislamiento- en régimen cerrado, primer grado, o en celdas de castigo, de mujeres sancionadas por infracciones menores y arbitrarias; perfil sociológico de pobreza y exclusión; problemáticas no resueltas en relación con las toxicomanías; sobrerrepresentación de las mujeres gitanas presas y aumento de las extranjeras en las cárceles por "trapicheo y menudeo» en el trafico de drogas; falta de apoyo social y psicológico en el caso de violencias machistas; etc. Todo ello sigue caracterizando a las distintas realidades de las cárceles de mujeres, que continúan siendo "agente discriminador de género» y no se rompe esa 
histórica escisión entre lo que se dice en la academia y se implementa después en las cárceles. La cárcel deviene una buena atalaya donde observar y constatar las dinámicas colectivas, porque el sistema penal y penitenciario es un buen reflejo de la modalidad de bienestar que cada sociedad desarrolla. Mujeres que se vulnerabilizan otra vez cuando entran en un sistema penitenciario que, pese a sus reformas o «supuestas mejoras», sigue discriminándolas, estereotipándolas, marginándolas y volviéndolas a excluir de una sociedad que ya las excluyó de entrada.

En el prólogo de un excelente libro sobre las mujeres presas en Argentina, Giuseppe Mosconi, criminólogo crítico italiano, expresa bien lo que significa y representa investigar la cárcel:

La cárcel representa seguramente uno de los terrenos más difíciles para la investigación social. No tanto y no sólo por los obstáculos burocráticos y formales, las restricciones espacio-temporales, el carácter rígido, inquietante, ansiógeno en los cuales la investigación se desarrolla, sino sobre todo por la red de ambigüedad de significados y de lenguajes dentro de la cual se debe interactuar, en distintos niveles. (Daroqui et al., 2006: 7)

Sin embargo, seguiremos insistiendo y analizando desde el feminismo. Ahora, con una base crítica mayor, con mucha más investigación que nos respalda, con redes colectivas, con entidades de mujeres presas. Porque siguen siendo necesarios mucho más estudio y mucha más divulgación para romper y dar la vuelta a las nuevas formas que va adoptando el control punitivo a las transgresoras de la ley penal.

\section{Referencias bibliográficas}

Acale, María (2011). "Mujeres, crímenes y castigos». Revista Hachetetepé, 2, 13-32. Adler, Freda (1975). Sisters in Crime. Nueva York: McGraw-Hill.

Almeda Samaranch, Elisabet (1992). «El control social sobre la mujer». Revista Poder y Libertad, 19, 6-9.

- (1994a). "L'associacionisme altruista en el sistema de justícia penal: El cas de Catalunya». Actes del II Congrés Català de Sociologia. Girona: Associació Catalana de Sociologia.

- (1994b). «Mujeres y cárcel. Dona i presó. Con Pepi Sánchez». Actas del encuentro Juntas y por Todas. Barcelona: Federación de Organizaciones Feministas del Estado Español.

- (1996). «Mujeres y prisión». Actas del congreso Las transformaciones del Estado y del derecho contemporáneo: Grupos emergentes y jóvenes investigadores. Oñati: International Institute for the Sociology of Law.

- (coord.) (1997). "Una aproximació a la situació de les dones empresonades de l'Hospitalet de Llobregat». Programa Municipal per a la Dona. Equip de recerca del Centre d'Atenció i Informació de la Dona. L'Hospitalet de Llobregat: Servei de Publicacions del Programa Municipal per a la Dona.

- (1998). "Avance del estudio de caso realizado en la cárcel de mujeres de Brians». En: Bodelón, Encarna y Picontó, Teresa (coord.). Transformaciones del Estado 
y del Derecho Contemporáneos: Nuevas perspectivas de la investigación socio-jurídica. Madrid: Dykinson.

- (1999). Passat i present de les presons de dones: Un estudi de cas al centre penitenciari de Brians. Servei de Publicacions. Universitat Autònoma de Barcelona. Edición microfotográfica.

- (2001). «Particularidades de las cárceles de mujeres: Un enfoque de género». Revista Panóptico. Monográfico «Mujer y cárcel», 2, 135-153.

- (2002). Corregir y castigar: El ayer y hoy de las cárceles de mujeres. Barcelona: Ediciones Bellaterra.

- (2003). Mujeres encarceladas. Barcelona: Ariel.

- (2005a). "Women's imprisonment in Spain», Punishment and Society: The International Journal of Penology [en línea], 7 (2), 183-199. Londres: Sage Publications. <https://doi.org/10.1177/1462474505050442>.

- (2005b). «Pasado y presente de las cárceles femeninas en España». Sociológica: Revista de Pensamiento Social, 6, 75-106.

- (2005c). «Las experiencias familiares de las mujeres encarceladas: El caso de Cataluña». En: Las cárceles de la democracia: Del déficit de ciudadanía a la producción de control. Madrid: Ediciones Bajo Cero.

- (2009). «Por unas nuevas estadísticas de la ejecución penal femenina». En: NicoLÁs, Gemma y Bodelón, Encarna (comp.). Género y dominación: Críticas feministas del derecho y el poder. Barcelona: Anthropos.

- (2010). «Privación de libertad y mujeres extranjeras: Viejos prejuicios y nuevas desigualdades». En: AÑaños, Fanny T. (coord.). Las mujeres en las prisiones: La educación social en contextos de riesgo y conflicto. Barcelona: Gedisa.

Almeda Samaranch, Elisabet y Bodelón, Encarna (ed.) (2007). Mujeres y castigo: Un enfoque socio-juridico y de género. Madrid: Dykinson.

Almeda Samaranch, Elisabet y Di Nella, Dino (2011). "Extranjeras encarceladas: Olvidos y desigualdades». Revista Hachetetepé, 2, 33-45.

Almeda Samaranch, Elisabet, Di Nella, Dino y Ballesteros, Ana (eds.) (2014). Mujeres y ejecución penal: Debates y experiencias en España desde una perspectiva intersectorial. Barcelona: Copalqui Editorial.

Almeda Samaranch, Elisabet; Di Nella, Dino y Navarro, Carmen (2012). «Mujeres, cárceles y drogas: Datos y reflexiones». Oñati Socio-Legal Series, 2 (6), 122-145.

Añaños, Fanny (coord.) (2010). Las mujeres en las prisiones: La educación social en contextos de riesgo y conflicto. Barcelona: Gedisa.

AÑaños, Fanny y Jiménez, Francisco (2016). «Población y contextos sociales vulnerables: La prisión y el género al descubierto». Papeles de Población, 87, 63-101.

AÑaños, Fanny y Yagüe, Concepción (2013). «Presentación. Educación social en prisiones. Planteamientos iniciales y políticas encaminadas hacia la reinserción desde la perspectiva de género». Pedagogía Social: Revista Interuniversitaria [en línea], 22, 7-12. <https://doi.org/10.7179/psri_2013.22.01>.

Aróstegi, Elisabete et al. (2008). Prisión y género: Efectos del encarcelamiento en mujeres $y$ hombres presos y su entorno familiar. Bilbao: Zubiko.

Ballesteros, Ana y Almeda Samaranch, Elisabet (2015). "Políticas de igualdad en las cárceles del siglo xxi: Avances, retrocesos y retos en la práctica del encarcelamiento femenino". Praxis Sociológica, 19, 161-186.

Balmaseda, Juana y Carrera, María (1995). «Discriminación de la mujer en el ámbito penitenciario». Noveno Congreso Estatal de Mujeres Abogadas, organizado por la Coordinadora Estatal de Mujeres Abogadas. Alicante, del 2 al 4 de noviembre. 
Barbeito, Isabel (ed.) (1991). Cárceles y mujeres en el siglo XVII. Madrid: Castalia / Instituto de la Mujer.

Barberet, Rosemary (2014). Women, Crime and Criminal Justice: A Global Enquiry. Londres: Routledge.

Barranquero, Encarnación et al. (1994). Mujer, cárcel, franquismo: La Prisión Provincial de Málaga (1937-1945). Málaga: Junta de Andalucía.

Beristain, Antonio; Cuesta, José de la (comp.) (1989). Cárcel de mujeres. Bilbao: Ediciones Mensajero.

Bernard, April (2012). "The Intersectional Alternative: Explaining Female Criminality». Feminist Criminology [en línea], 8 (1), 3-19. <https://doi.org/10.1177/1557085112445304>.

Bertrand, Marie-Andrée (1969). «Self image and delinquency: A contribution to the study of female criminality and woman's image». Acta Criminológica [en línea], 2, 71-144. <https://doi.org/10.7202/017007ar>.

Bertrand, Marie-Andrée (1994). «From la donna delinquente to a postmodern deconstruction of the woman question». Social Control Theory, Journal of Human Justice [en línea], 5 (2), 43-57. $<$ https://doi.org/10.1007/bf02585452>.

- (1996). "Women in Prisons: A Comparative Study». Caribbean Journal of Criminology and Social Psychology, 1 (1), 35-58.

Bodelón, Encarna y Bergalli, Roberto (1992). "La cuestión de las mujeres y el derecho penal simbólico». Anuario de Filosofía del Derecho, IX, 43-73.

Bona, Remei (1992). "Control judicial, libertad condicional: Reinserción de las penadas». Fòrum sobre dones empresonades, organizado por la Asociación Catalana de Mujeres de Carreras Jurídicas. Barcelona.

- (1994). «La función rehabilitadora de la pena de Privación de libertad: Entre el discurso teorico y el fracaso». Jornades de mesures alternatives a la presó, organizadas por el Grupo de Prisiones de la Comisión de Defensa del Colegio de Abogados de Barcelona.

Bosworth, Mary (1999). Engendering resistance: Agency and power in Women's prisons. Aldershot: Ashgate.

Bosworth, Mary y CARrabine, Eamonn (2001). «Reassessing resistance: Race, gender and sexuality in prison». Punishment and Society, 3 (4), 501-515.

Bueno Arús, Francisco (1995). "La mujer y el sistema penitenciario español». Poder Judicial, 39, 65-95.

Burgess-Proctor, Amanda (2006). "Intersections of Race, Class, Gender, and Crime: Future Directions of Feminist Criminology». Feminist Criminology [en línea], 1 (1), 27-47. <https://doi.org/10.1177/1557085105282899>.

Campelli, Enzo et al. (1992). Donne in carcere: Ricerca sulla detenzione femminile in Italia. Milán: Feltrinelli.

Canteras Murillo, Andrés (1990). Delincuencia femenina en España: Un análisis sociológico. Madrid: Ministerio de Justicia.

Carbonell, Montserrat (1997). Sobreviure a Barcelona: Dones, pobresa i assistència al segle XVIII. Vic: Eumo Editorial.

CARIO, Robert (1989a). La criminalité des femmes. Tolosa: Erès.

- (1989b). «Particularidades de la situación carcelaria de las mujeres». En: Beristain, Antonio y Cuesta, José de la (comp.). Cárcel de mujeres. Bilbao: Ediciones Mensajero. 
Carlen, Pat (1983). Women's imprisonment: A study in Social control. Londres: Routledge.

- (1990). Alternatives to Women's Imprisonment. Filadelfia: Open University Press.

- (1998). Sledgehammer: Women's Imprisonment at the Millenium. Londres: Palgrave Macmillan.

Carlen, Pat et al. (1985). Criminal Women: Autobiographical Accounts. Cambridge: Polity Press.

Carlen, Pat y Worrall, Anne (2004). Analysing Women's Imprisonment. Oregon: Willan Publishing.

- (eds.) (1987). Gender, Crime and Justice. Filadelfia: Open University.

Carrington, Kerry (1993). «Essentialism and feminist criminologies: Relevant to all specific to none!». Critical Criminology, 5, 5-20.

Castillo, Joaquina y Ruiz, Marta (2006). «Mujer extranjera en la prisión española actual». En: Bosch, Esperança et al. (comp.). Los feminismos como herramientas de cambio social (I): Mujeres tejiendo redes históricas, desarrollos en el espacio público y estudios de las mujeres. Palma de Mallorca: Universidad de las Islas Baleares.

- (2010). "Mujeres extranjeras en prisiones españolas: El caso andaluz». Revista de Investigaciones Sociológicas [en línea], 68 (2), 473-498. <https://doi.org/10.3989/ris.2008.05.15>.

Cervello Donderis, Vicenta (2006). «Las prisiones de mujeres desde una perspectiva de género». Revista de Estudios Penitenciarios, Extra Año 2006, 129-150.

Chesney-Lind, Meda (1989). "Girl's crime and woman place: Toward a feminist model of female delinquency». Crime and Delinquency [en línea], 35, 5-29. $<$ https://doi.org/10.1177/0011128789035001002>.

Chesney-Lind, Meda y Morash, Merry (2013). "Transformative Feminist Criminology: A Critical Re-thinking of a Discipline». Critical Criminology [en línea], 21 (3), 287-304. <https://doi.org/10.1007/s10612-013-9187-2>.

Clemente, Miguel (1987a). Delincuencia femenina: Un enfoque psicosocial. Madrid: UNED.

- (1987b). «La delincuencia femenina I: Concepto, tratamiento histórico del problema». En: Sancha, Víctor et al. Delincuencia: Teoría e investigación. Madrid: Alpe Editores.

Cомаск, Elizabeth (1999). «New possibilities for a feminism in criminology?: Form dualism to diversity». Canadian Journal of Criminology, 41, 161-171.

Council of Europe (2015). Space I 2014: Facts and Figures. Luxemburgo: Council of Europe.

Cowen, Philip (1979). "An XYY Man». British Journal of Psychiatry, 135 (1), 78-81.

Crites, Laura (ed.) (1976). The female offender. Massachussets: Lexington Books.

Cruells, Marta et al. (2005). Violencia contra las mujeres: Análisis de la población penitenciaria femenina. Barcelona: SURT.

Cruells, Marta e Igareda, Noelia (coord.) (2006). Mujeres, integración y prisión. Barcelona: Aurea. SURT.

Cuevas Gutiérrez, Tomasa (1982). Cárcel de mujeres. Madrid: Ediciones de la Casa de Campo.

Daly, Kathleen y Chesney-Lind, Meda (1988). «Feminism and criminology». Justice Quarterly, 5 (4), 497-538.

Dapena, María Francisca (1978). jSr. Juez! (Soy presa de Franco...). San Sebastián: L. Haramburu. 
Daroqui, Alcira et al. (2006). Voces del encierro. Mujeres y jóvenes encarcelados en Argentina: Una investigación socio-jurídica. Buenos Aires: Omar Favale Ediciones Jurídicas.

Davis, Angela (1996). «Incarcerated Women: Transformative Strategies». Black Renaissance, 1, 21-38.

Davis, Angela y Bhavnani, Kum-Kum (2000). «Women in prison: Researching Race in Three National Contexts». En: Winddance, France y Warren, Jonathan. Racing Research, Researching Race Methodological Dilemmas in Critical Race studies. Nueva York: University Press.

Del Val-Cid, Consuelo; Viedma-Rojas, Antonio y Reviriego-Picón, Fernando (2013). «Hacia una medida objetiva de la discriminación en la cárcel: indicadores e índice de punición». Revista Criminalidad, 55 (2), 29-47.

Dirección General de Instituciones Penitenciarias (2009a). Programa de Acciones para la Igualdad entre Mujeres y Hombres en el Ámbito Penitenciario Español. Madrid: Ministerio del Interior.

- (2009b). Preámbulo de la creación de la comisión técnica del Programa de Acciones para la Igualdad entre Mujeres y Hombres en el Ámbito Penitenciario Español. Madrid: Ministerio del Interior.

Dobash, Rebecca; Dobash, Rusell y GutTteridge, Sue (1986). The imprisonment of Women. Oxford: Blackwell.

Doña, Juana (1978). Desde la noche y la niebla (Mujeres en las cárceles franquistas). Novela-testimonio. Madrid: Ediciones De la Torre.

Emakume Eta Justizia (SAlhaKeta) (1994). Informe general sobre las cárceles de mujeres. Vitoria: Salhaketa.

EQUipo BARAÑi (2001). Mujeres gitanas y sistema penal. Madrid: Ediciones Meytel.

European Comission (2006). Women, Integration and Prison: An analysis of the processes of sociolabour integration of women prisoners in Europe. MIP Project. Luxemburgo: Office for Oficial Publications of the European Communities.

FACCioli, Franca (1982). «L'identitá negata: Analisi del carcere femminile». Devianza ed Emarginazione, 4, 174-185.

FAlcón, Lidia (1977). En el infierno: Ser mujer en las cárceles de España. Barcelona: Ediciones del Feminismo.

FARrington, David y Morris, Allison (1983). «Sex sentencing and reconviction». British Journal of Criminology, 3 (23), 229-248.

FERnÁndeZ, Marisa et al. (1995). «La discriminación por razón de sexo en el Derecho Penitenciario». Noveno Congreso Estatal de Mujeres Abogadas, organizado por la Asociación Española de Mujeres Abogadas. Barcelona, 20 de octubre.

Fiestas Loza, Alicia (1978). «Las cárceles de mujeres». Historia 16, extra viI, 91-99.

FOnTANIL, Yolanda et al. (2013). «Mujeres en prisión: Un estudio sobre la prevalencia del maltrato». Revista Española de Sociología, 2, 21-38.

Frances, Paz y Serrano, Guadalupe (2011). Mujeres en prisión: Voces desde dentro del centro penitenciario de Pamplona. Pamplona: Salhaketa.

García Mas, María Pepa et al. (1987). La droga en una cárcel de mujeres. Madrid: Instituto Regional de Estudios (IRES).

- (1989). Juventud femenina marginal: Delincuencia y drogas. Madrid: Instituto de la Mujer.

Gea Fernández, María José et al. (2014). Una condena compartida: Un estudio de caso sobre el control penal. Madrid: Tierradenadie.

Gelsthorpe, Loraine (2010). "Women, Crime and Control». Criminology and Criminal Justice, 10 (4), 375-386. 
Gelsthorpe, Loraine y Morris, Allison (eds.) (1990). Feminist Perspectives in Criminology. Milton Keynes: Open University Press.

- (2002). "Women's Imprisonment in England and Wales: A Penal Paradox». Criminal Justice [en línea], 2 (3), 277-301. <https://doi.org/10.1177/17488958020020030301>.

Genders, Elaine y Player, Elaine (1987). «Women in Prison: The Treatment, the Control and the Experience». En: Carlen, Pat y Worrall, Anne (eds.). Gender, Crime and Justice. Filadelfia: Open University.

Giacobee, Thea (2014). «Le donne in esecuzione penale: Analisi di una marginalitat in Sicilia». Rassegna Penitenziaria e Criminològica, 3, 87-127.

Giallombardo, Rose (1966). Society of women: Study of a Women's Prison. Nueva York: Wiley.

Gibson, Helen (1976). «Women’s prisons: Laboratories of penal reform». En: CRITES, Laura (ed.). The female offender. Massachussets: Lexington Books.

Giménez-Salinas, Esther; Rifà i Ros, Anna (1992). Introducció al Dret Penitenciari: Teoria i pràctica. Barcelona: Centre d'Estudis Jurídics i Formació Especialitzada.

Grup Dona i Presó (1995). Presó i dona. Barcelona: El Crit de l'Òliba.

Gutiérrez, Cristina (1997). La Casa de Correcció de Barcelona (1836-1856). Barcelona: Departament d'Història Moderna i Contemporánia i Centre d'Estudis Jurídics i Formació Especialitzada.

Hahn Rafter, Nicole y Heidensohn, Frances (ed.) (1995). International Feminist perspectives in Criminology: Engendering a discipline. Open University Press: Buckingham.

Haney, Lynne (2010). Offending women: Power, punishment and the regulation of desire. Berkeley: University of California Press.

Hannah-Moffat, Kelly (2001). Punishment in disguise: Penal Governance and Federal Imprisonment of Women in Canada. Toronto: University of Toronto Press.

Hayward, Keith et al. (eds.) (2010). Fifty Key Thinkers in Criminology. Londres. Routledge.

Heidensohn, Frances (1968). "The deviance of women: A critique and enquiry». British Journal of Sociology [en línea], 19 (2), 160-175. <https://doi.org/10.1111/j.1468-4446.2009.01242.x>

- (1985). Women and Crime. Londres: Macmillan.

Hernández Holgado, Fernando (2003). Mujeres encarceladas: La prisión de Ventas. De la República al franquismo, 1931-1941. Madrid: Marcial Pons.

- (2013). "Cárceles de mujeres del novecientos: Una rutina punitiva secular». Segle XX: Revista Catalana d'Història, 6, 85-112.

- (2015). "Juana Doña y el manantial de la memoria: Memorias de las cárceles franquistas de mujeres (1978-2007)». Arenal: Revista de Historia de Mujeres, 22 (2), 289-309.

Herrera, Myriam (1993). «Mujeres y prisión». Cuadernos de Política Criminal, 49, 339-354.

IgAreda, Noelia (2009). «La maternidad de las mujeres presas». En: Nicolás, Gemma y Bodelón, Encarna (comp.). Género y dominación: Críticas feministas del derecho y el poder. Barcelona: Anthropos.

ImAZ, Elixabete (2007). «Mujeres reclusas, mujeres invisibles». En: Biglia, Barbara y SAN MARTín, Conchi (coords.). Estado de wonderbra: Entretejiendo narraciones feministas sobre las violencias de género. Barcelona: Virus Editorial. 
Juliano, Dolores (2011). Presunción de inocencia: Riesgo, delito y pecado en femenino. Donostia-San Sebastián: Gakoa.

LARraUri, Elena (comp.) (1994). Mujeres, derecho penal y criminología. Madrid: Siglo XXI.

LlorCa, José (1992). Cárceles, presidios y casas de corrección en la Valencia del XIX (Apuntes históricos sobre la vida penitenciaria valenciana). Valencia: Tirant lo Blanch.

Lombroso, Cesare y Ferrero, William (1895). The Female Offender. Londres: Fisher Unwin.

Manzanos, Cesar y Balmaseda, Juana (2003). Situación de las mujeres en las cárceles del País Vasco. Donostia-San Sebastián: Gobierno Vasco.

Mapelli Caffarena, Borja et al. (2012). Mujeres en las cárceles de Andalucía. Madrid: Dykinson.

- (2013). «La exclusión de las excluidas. ¿Atiende el sistema penitenciario a las necesidades de género?: Una visión andaluza». Estudios Penales y Criminológicos, 33, 59-95.

Martín, Teresa; Miranda, Jesús y Vega, Cristina (eds.) (2005). Delitos y fronteras: Mujeres extranjeras en prisión. Madrid: Universidad Complutense.

Martínez, Gema (2002). Galerianas, corrigendas y presas: Nacimiento y consolidación de las cárceles de mujeres en España (1608-1913). Madrid: EDISOFER.

Mednick, Sarnoff (1987). The Causes of Crime: New Biological Approaches. Cambridge: Cambridge University Press.

Miguel Calvo, Estibaliz de (2016). Relaciones amorosas de las mujeres encarceladas. Bilbao: UPV/EHU Servicio Editorial.

Miralles, Teresa (1983). «La mujer: El control formal». En: Bergalli, Roberto et al. El pensamiento criminológico II: Estado y control. Bogotá: Temis.

Miranda, María Jesús (2002). «Cárceles ¿Para qué?». Politica y Sociedad, 39 (2), 377-397.

Morris, Allison (1987). Women, Crime and Criminal Justice. Oxford: Basil Blackwell.

NAfFine, Ngaire (1987). Female crime: The construct of women in criminology. Sidney: Allen and Allen.

NAREdo, María (2004). «¿Qué nos enseñan las reclusas?: La criminalización de la pobreza desde la situación de reclusas extranjeras y gitanas». Humanismo y Trabajo Social, 3, 67-94.

- (2007). "Reclusas con hijos/as en la cárcel». En: ALMEDA, Elisabet y BodELón, Encarna (ed.). Mujeres y Castigo: Un enfoque socio-jurídico y de género. Madrid: Dykinson.

O’Dwyer, Josie et al. (1987). "Women's imprisonment in England, Wales and Scotland: Recurring issues». En: Carlen, Pat y Worrall, Anne (eds.). Gender, Crime and Justice. Milton Keynes-Filadelfia: Open University.

Organización de las Naciones Unidas (2011). Reglas de las Naciones Unidas para el tratamiento de las reclusas y medidas no privativas de la libertad para las mujeres delincuentes. Reglas de Bangkok. Nueva York: Naciones Unidas.

PÀmies, Teresa (1975). Dona de pres. Barcelona: Proa.

Pi-Sunyer, Teresa y Vendrell, Núria (1988). Qualitat de vida al centre penitenciari de dones Wad-Ras de Barcelona. Barcelona. Treball inèdit.

- (1992). «La maternitat a les presons de dones». Fòrum sobre dones empresonades, organizado por la Asociación Catalana de Mujeres de Carreras Jurídicas. Barcelona, 28 de marzo.

Pollack, Otto (1961). The Criminality of Women. Nueva York: Barnes.

Renzetti, Claire (2013). Feminist criminology. Londres: Routledge.

Ribas, Natalia; Almeda Samaranch, Elisabet y Bodelón, Encarna (2005). Rastreando lo invisible: Mujeres inmigrantes en las cárceles. Barcelona: Anthropos. 
Roig, Aura (2012). "La violencia de genere, el sistema penal i l'autonomia de les dones». Revista Critica Penal y Poder, 2, 163-179.

Seear, Nancy y Player, Elaine (1986). Women in the Penal System. Londres: Howard League.

Sepúlveda, Pilar (1995). «Situación de la mujer reclusa en el sistema penitenciario español». Noveno Congreso Estatal de Mujeres Abogadas, organizado por la Coordinadora Estatal de Mujeres Abogadas. Alicante, del 2 al 4 de noviembre.

Smart, Carol (1976). Women, Crime and Criminology. Londres: Routledge.

Smith, Ann (1962). Women in Prison. Londres: Stevens.

SURT (2008). Abordando la violencia de género en prisión: Manual de programas penitenciarios contra la violencia de género. Barcelona: Aurea.

Telo Nuñez, María (1995). Concepción Arenal y Victoria Kent. Las prisiones: Vida y obra. Madrid: Instituto de la Mujer.

Thomas, William (1967). The Unadjusted Girl. Nueva York: Harper \& Row.

Val Cid, Consuelo del y Viedma, Antonio (ed.) (2012). Sistema de indicadores de discriminación penitenciaria. Barcelona: Icaria.

VinYes, Ricard (2000). «Res no us pertany...: Les preses de Barcelona, 1939-1945». L'Avenç, 251, 18-25.

- (2002). Irredentas: Las presas políticas y sus hijos en las cárceles franquistas. Barcelona: Temas de Hoy.

Ward, David y Kassebaum, Gene (1966). Women's Prison. Londres: Weidenfeld and Nicolson.

Worrall, Anne (1990). Offending Women. Londres: Routledge.

Worrall, Anne y Gelsthorpe, Loraine (2009). «What works' with women offenders: The past 30 years». Probation Journal [en línea], 56 (4), 329-345. <https://doi.org/10.1177/0264550509346538>.

YAGÜE, Concepción (2002). «Mujer: delito y prisión: Un enfoque diferencial sobre la delincuencia femenina». Revista de Estudios Penitenciarios, 249, 1-39.

- (2006a). «Las mujeres encarceladas». En: Calvo, Adelina et al. (eds.) (2006). Mujeres en la periferia: Algunos debates sobre género y exclusión social. Barcelona: Icaria.

- (2006b). Madres en prisión: Historia de las cárceles de mujeres a través de su vertiente maternal. Granada: Comares.

- (2007). «Mujeres en prisión: Intervención basada en sus características, necesidades y demandas». Revista Española de Investigación Criminológica, 4 (5), 1-24.

- (2011). «Panorama actual de la situación de las mujeres y madres en los centros penitenciarios españoles: El programa de igualdad». En: AÑaños, Fanny (coord.). Las mujeres en las prisiones: La Educación Social en contextos de riesgo y conflicto. Barcelona: Gedisa.

- (2012). "Políticas de género y prisión en España». En: VAL, Concepción del y Viedma, Antonio (eds.). Condenadas a la desigualdad: Sistema de indicadores de discriminación penitenciaria. Barcelona: Icaria.

- (2014). «Políticas y medidas para la igualdad y la infancia en las prisiones españolas: Logros y retos». En: Almeda, Elisabet; Di Nella, Dino y Ballesteros, Ana (eds.). Mujeres y ejecución penal: Debates y experiencias en España desde una perspectiva intersectorial. Barcelona: Copalqui. 